experiment. In other words the alchemist, starting from a sort of chemistry, discovered that he could experience visions which, though expressed in a chemical language, are expressions of the collective unconscious.

Jung's analysis of alchemy is undoubtedly the most penetrating that any psychologist has attempted and it is especially illuminating because he relates it to other expressions of the individuation process, namely Christianity and Gnosticism.

The discovery of the "objective psyche", as the collective unconscious is sometimes called, and its processes has a significant bearing upon the problem of personality. This is the subject of the last chapter. It is only by inference therefore that it can be made to cohere with the rest of the book. The chapter is couched in cautious terms and represents Jung's contribution to a problem which he does not regard as having reached a solution or to be defined; he relates it to the Chinese concept of Tao which cannot be defined, it is simply an experience.

As with all Jung's books he goes beyond the limits of specialization so that this book can be read not only by a specialist but also by the general reader.

M.F.

Arithmetic is Easy. By M. M. Rogers, M.A. 100 pages. Evans Bros., Ltd., London. 3s. $6 \mathrm{~d}$.

My first reaction on reading Miss Rogers' delightful book was one of deep regret for all the hours of suffering I had passed through because I had not read her book when I was in the schoolroom, and incidentally neither had my teachers !

Those of us who have to deal with difficult and sensitive children find that a large proportion of them have great difficulty in grasping arithmetic as it is taught in school. Although in many cases it is obvious that there are emotional factors underlying the difficulty it is also clear that they have failed to understand the subject because it has not been presented to them in a way which was suited to their mentality.

A common difficulty to which Miss Rogers refers is due to insufficient repetition of elementary rules; thus a child who has missed a few weeks' schooling finds itself completely out of its depth on its return, and so becomes discouraged and defeatist in its outlook. Children's minds are so logical that if arithmetic were represented to them as a reasonable thing in the manner suggested by Miss Rogers, and if all the examples were related to real situations, as she suggests, there is little doubt but that they would find arithmetic a pleasure. As she so truly says it is the one subject in which one can attain absolute perfection. If a sum is right it is right, and by the method of self checking which she advocates the child can have all the pleasure of demonstrating the correctness of its own work.

One common difficulty results from the different methods employed by different teachers, sometimes even in the same school. Surely the pundits can agree on some uniform procedure; the more so as it is a matter of perfect indifference to the average adult and all that is required is a method that will yield accurate results.

Everyone should read Miss Rogers' little book, even those fortunate ones who have not suffered themselves, for it will certainly enlarge their horizon and give them a clearer outlook. It is specially to be recommended to educational psychologists and psychiatric social workers who have to deal with problems of school children. Would that all methematical teachers were as understanding and clear minded as the author of this book.

\section{THE TAVISTOCK CLINIC}

The Clinic announce particulars of Lecture Courses for the Academic year 1940-1941 for Teachers, Educationalists, London University students and those trained for work with children. Among these are courses on Mental Health in Childhood (Child Development and Training, Common Disorders of Childhood), Elementary Mental Testing, and a course on Mental Hygiene arranged at the request of King's College, London. Full particulars may be had on application to the Educational Secretary, The Tavistock Clinic, Kidderpore Avenue, N.W.3.

\section{TWO \\ C.A.M.W. PUBLICATIONS}

CHILDREN WHO CAN NEVER
GO TO SCHOOL - $3 \frac{1}{2} \mathrm{~d}$. post free
SPEECH TRAINING - $6 \frac{1}{2} \mathrm{~d}$. post free

24 Buckingham Palace Road London, S.W.1 